\title{
AÇÕES INTERGERACIONAIS: RESPEITO E VALORIZAÇÃO DOS IDOSOS
}

\section{Actions between generations: respect and the valorization of the elderly \\ Acciones intergeneracionales: respeto $y$ valoración de los ancianos}

\author{
Márcia Carréra Campos Leal ${ }^{1}$ \\ Ana Paula de Oliveira Marques ${ }^{2}$ \\ Sílvia Carréra Austregésilo 3
}

\begin{abstract}
RESUMO
Uma política para o envelhecimento deve manter na comunidade o maior número de idosos. Nessa premissa, a incorporação de práticas alternativas de assistência a este segmento populacional deve valorizar um modo de vida ativo e integrado. Atualmente o descaso, o desrespeito e a falta de paciência dos jovens para com os idosos vem crescendo, gerando conflitos entre gerações e exclusão dos idosos. Tal situação sugere uma reorientação da compreensão do envelhecimento já na escola, com a participação dos idosos reforçando valores $e$ atitudes positivas em relação à velhice, com estímulo ao exercício da cidadania $e$ solidariedade. Objetivos: estimular no aprendizado da $1 .^{\mathrm{a}}{ }^{\mathrm{à}} 4 .^{\mathrm{a}}$ séries o respeito e a valorização aos idosos; vivenciar de forma lúdica o conhecimento da cultura e da história do nosso povo; elevar a autoestima do idoso usando o seu conhecimento na relação intergeracional; elaborar uma cartilha com as brincadeiras vivenciadas durante a execução do projeto. Metodologia: dinâmicas de grupos; oficinas de sensibilização e capacitação, trabalhos em pequenos grupos e discussão circular. Resultado: participaram 180 alunos e 10 professores da rede estadual do ensino fundamental, 141 avós e 4 alunas dos cursos de graduação da UFPE, num processo de aprendizado. Conclusão: o projeto despertou nas crianças o aprender, brincar $\boldsymbol{e}$ crescer com respeito e solidariedade aos idosos, bem como favoreceu a autoestima e a melhoria da qualidade de vida dos mais velhos, num convívio intergeracional.
\end{abstract}

Palavras-chave: gerontologia; qualidade de vida; convívio intergeracional; autoestima.

\begin{abstract}
Introduction: A politic based on the elderly should consist on keeping them acting in the society. So, it is really important to create ways for the aged population to become an active part of the society. Nowadays the neglect, disrespect and lack of patience from younger people in relation to the elderly is growing and creating conflicts between generations and elderly exclusion. Such situation points to a reorientation to understand aging with the younger still in school, with elderly participation reinforcing positive values and attitudes related to the old age encouraging citizenship and solidarity. Objectives: Stimulate the learning of the $1^{\text {st }}$ to $4^{\text {th }}$ grade to respect and valorization of the elderly, live with a playful knowledge the culture and history of our people; rising the elderly self-steam using their knowledge in intergenerational relation; create a learning book with games experienced during project implementation. Methodology: groups dynamic, awareness and training workshops, workshops for small groups and circular discussion. Results: One hundred and eighty students and 10 professors of public schools, 141 grandparents and 4 students of graduate course the UFPE participated in this study, in a process of learning. Conclusions: This project awakened in
\end{abstract}

1 Doutora em Odontologia, Professora Adjunta III do Departamento de Medicina Social da Universidade Federal de Pernambuco/ UFPE, Coordenadora do Núcleo de Atenção ao Idoso - NAI/UFPE - Endereço: Rua Dr. João Santos Filho - 250/1901 - Casa Forte - Recife/PE - CEP 52060-616 - Telefone: (81) 3441-3445 - (81)9101 9212. E-mail: marciacarrera@hotmail.com.

2 Doutora em Nutrição, Professora Adjunta II do Departamento de Medicina Social da Universidade Federal de Pernambuco/UFPE, Coordenadora do Programa do Idoso - PROIDOSO - e da Universidade Aberta da Terceira Idade - UnATI/UFPE.

3 Aluna do Curso de Odontologia da Universidade Federal de Pernambuco/UFPE.

Fonte de Financiamento: Recursos para Financiamento de Apoio a Ações Extensionistas - PROEXT/UFPE. 
the children learn, play and grow respect and solidarity to the elderly, as well as was helpful to self-steam and improving older people life quality in an intergeneration interaction.

Keywords: gerontology; life quality; intergeneration interaction; self-steam.

\section{RESUMEN}

Introducción: Una política para la vejez debe mantener en la comunidad lo mayor número posible de ancianos. En esa premisa, la incorporación de prácticas alternativas de asistencia a este segmento poblacional debe valorar un modo de vida activo y integrado. Actualmente el descaso, el desacato y la falta de paciencia de los jóvenes, para con los ancianos viene creciendo, generando conflictos entre generaciones y exclusión de los ancianos. Esta situación sugiere una reorientación de la comprensión de la vejez ya en la escuela, con la participación de los ancianos reforzando valores y actitudes positivas en relación a la vejez, con estímulo al ejercicio de la ciudadanía y solidaridad. Objetivos: estimular en el aprendizaje de la $1 .^{\text {a }}$ hasta la $4 .^{\text {a }}$ serie el respeto y la valoración a los ancianos; vivenciar de forma lúdica el conocimiento de la cultura y de la historia de nuestro pueblo; elevar la autoestima del anciano usando su conocimiento en la relación intergeneracional; elaborar una cartilla con los chistes vivenciadas durante la ejecución del proyecto. Metodología: dinámicas de grupos; trabajos de sensibilización y capacitación, trabajos en pequeños grupos y discusión circular. Resultado: Participaron 180 alumnos y 10 profesores de las escuelas públicas de la enseñanza fundamental, 141 abuelas y 04 alumna de los cursos de graduación de la UFPE, en un proceso de aprendizaje. Conclusión: el proyecto despertó en los niños el aprender, bromear y crecer con respeto y solidaridad a los ancianos,bien como, favoreció la autoestima y la mejoría de la calidad de vida de los ancianos, en la convivencia intergeneracional.

Palabras-clave: gerontología; calidad de vida; convivencia intergeneracional; autoestima.

Introdução

O rápido envelhecimento populacional brasileiro registra, de acordo com dados do IBGE, 9,2\% de indivíduos com idade igual ou superior a 60 anos, caracterizando o Brasil como um país de velhos (IBGE, 2000; COELHO FILHO; RAMOS, 1999; PEREIRA, CURIONI, VERAS, 2003; CAMARANO, 2006). Nesse sentido, faz-se necessário preparar a população para entender o envelhecimento enquanto processo inerente ao curso da vida. O descaso, o desrespeito e a falta de paciência por parte da maioria dos jovens com os idosos vêm sendo registrados no comportamento e nas falas das crianças nos momentos de rotina, como nas rodas de conversas; na mídia, enfim, no dia a dia. Este comportamento leva a um conflito entre as gerações, proporcionando desconforto e exclusão social dos idosos (LEME, 2002; FALEIROS, 2007).

Tal situação leva-nos a acreditar numa reorientação destes jovens, com a participação dos idosos no âmbito da escola, iniciando desde a infância a formação de valores e atitudes importantes para o exercício da cidadania e solidariedade. Assim, o projeto tem como objetivos: estimular o aprendizado de estudantes da 1. à 4. ${ }^{a}$ séries sobre o respeito e a valorização aos idosos; vivenciar de forma lúdica o conhecimento da cultura e da história do nosso povo; elevar a autoestima do idoso, usando o seu conhecimento na relação intergeracional; e elaborar uma cartilha com as brincadeiras vivenciadas durante a execução do projeto.

\section{Metodologia}

Trata-se do relato de experiência de um projeto de extensão desenvolvido no período de 2006 a 2007 em uma Escola Estadual do município de Recife/PE.

Participaram do projeto 180 alunos da rede estadual da $1 .^{a}$ à $4 .^{a}$ séries do ensino fundamental, sendo 92 do turno da manhã e 88 do turno da tarde; 10 professores da rede estadual; 141 avós e quatro alunas dos 
cursos de graduação da Universidade Federal de Pernambuco-UFPE. Foi estabelecido no projeto como critério de inclusão apenas as avós, em virtude da dificuldade de participação dos avôs, considerando o horário - manhã/tarde - de execução do projeto, turno que em geral os homens exercem alguma atividade laborativa.

Visando à capacitação e à sensibilização dos participantes, foram utilizadas como estratégias dinâmicas de grupo e realizadas oficinas temáticas e seminários. Para o desenvolvimento das atividades, inicialmente houve a divisão em pequenos grupos, tanto dos alunos como dos grupos das avós e, posteriormente, agrupamento destes pequenos grupos, formando um grande grupo, trabalhando temas diversos. Durante a execução do projeto foi elaborado uma cartilha com as atividades vivenciadas, estes procedimentos obedeceram às seguintes etapas:

- Sensibilização e capacitação dos alunos da graduação envolvidos no projeto;

- Oficinas com os professores da rede estadual;

- Palestra para os alunos;

- Oficinas com as avós dos alunos;

- Atividades intergeracionais (avós, alunos, professores e monitores);

- Elaboração do relatório final e da cartilha com as experiências vivenciadas.

Assim, num processo de contínuo de aprendizado, houve semanalmente atividades realizadas com os estudantes de graduação, com o objetivo de sensibilizar e capacitar no conhecimento gerontológico. Os professores da rede estadual participaram de duas oficinas com o objetivo de integração, sensibilização e incorporação de conhecimentos específicos sobre o projeto; duas palestras (uma no turno da manhã e uma no turno da tarde) com os alunos, com apresentação de vídeos sobre "Velhice não é doença"; oficinas com as avós dos alunos, divididas em grupos de 20, para conhecimento da cultura popular vivenciada por esta geração, elevando a autoestima do idoso e usando o seu conhecimento na relação intergeracional; atividades de integração com todos os participantes do projeto; elaboração de uma cartilha com as brincadeiras de crianças vivenciadas durante a execução do projeto com a colaboração dos idosos.

\section{Resultado}

O número de alunos participantes da rede estadual foi de 180, sendo 92 do turno da manhã e 88 do turno da tarde, distribuído de acordo com a tabela 1 .

TABELA 1 - DISTRIBUIÇÃO DO NÚMERO DE ALUNOS DE ACORDO COM A SÉRIE E TURNO, RECIFE, 2007

\begin{tabular}{|c|c|c|c|}
\hline Série & Turno Manhã & Turno Tarde & Total \\
\hline $1 .^{\mathrm{a}}$ & 34 & 21 & 55 \\
\hline $2^{\mathrm{a}}$ & 18 & 32 & 50 \\
\hline $3^{\mathrm{a}}$ & 22 & 16 & 38 \\
\hline $4^{\mathrm{a}}{ }^{\mathrm{a}}$ & 18 & 19 & 37 \\
\hline Total & $\mathbf{9 2}$ & $\mathbf{8 8}$ & $\mathbf{1 8 0}$ \\
\hline
\end{tabular}

Das 141 avós participantes, 56 tinham idade entre 33 e 59 anos, abaixo do corte cronológico da Política Nacional do Idoso (60 anos) e 85 entre 60 e 88 anos; observamos como dificuldade na execução do projeto o não comparecimento das avós em todas as atividades intergeracionais, bem como o número de avós esperado ser inferior ao número de alunos, onde 180 alunos deveriam ter 360 avós (maternas e paternas); entretanto, alguns afirmaram não ter avós e outras não responderam ao convite para participar do projeto.

Ressaltamos que muitas destas avós fazem o papel de mães, em virtude das filhas/filhos, na maioria jovens, deixarem os cuidados com as crianças nas mãos das avós. 
Chama a atenção a faixa etária das avós, como apresentamos na tabela 2 , em que observamos um percentual de $10 \%$ entre 30-49 anos.

TABELA 2 - DISTRIBUIÇÃO DAS AVÓS DE ACORDO COM A FAIXA ETÁRIA, RECIFE, 2007

\begin{tabular}{|c|c|c|}
\hline Faixa Etária & $\mathbf{N .}^{\mathbf{o}}$ & $\mathbf{\%}$ \\
\hline $30-39$ & 06 & $4,3 \%$ \\
\hline $40-49$ & 08 & $5,7 \%$ \\
\hline $50-59$ & 42 & $29,8 \%$ \\
\hline $60-69$ & 44 & $31,2 \%$ \\
\hline $70-79$ & 26 & $18,4 \%$ \\
\hline 80 e mais & 15 & $10,6 \%$ \\
\hline Total & $\mathbf{1 4 1}$ & $\mathbf{1 0 0 \%}$ \\
\hline
\end{tabular}

Como resultado do projeto, elaboramos a cartilha Aprender, Brincar e Crescer como uma contribuição das atividades vivenciadas nas oficinas com as avós, resgatando antigas brincadeiras que estão um pouco esquecidas, estimulando a prática de brincadeiras divertidas e sociáveis, desenvolvendo as habilidades das crianças, Aprendendo, Brincando e Crescendo.

As brincadeiras que constam nessa cartilha são: Roda ou Cirandinha; Futebol; PularCorda; Pião; Esconde-Esconde; Bola de Gude; Pipa/Papagaio; Peteca; Bolha de Sabão; Cabo de Guerra, as quais são descritas a seguir.

\section{Atirei o pau-no-gato}

Atirei o pau no gato, tô, tô.

Mas o gato, tô, tô.

Não morreu, reu, reu.

Dona Chica, cá, cá.

Admirou, rô, rô, rô.

Do miau, do miau, que o gato deu.

Miauuuuuuuuuuuuuuu

\section{Ciranda, Cirandinha}

Ciranda, cirandinha, vamos todos cirandar;

Vamos dar a meia volta, volta e meia vamos dar.

$\mathrm{O}$ anel que tu me deste

Era vidro e se quebrou;

$\mathrm{O}$ amor que tu me tinhas

Era pouco, se acabou.

Nesta brincadeira as crianças, de mãos dadas, rodam e cantam. Algumas vezes, a brincadeira é enriquecida com pulos, rodopios ou cumprimentos.

\section{O Circo}

O circo pegou fogo,

A polícia deu sinal de acuda,

Acuda a bandeira nacional, 1, 2, 3,

Alô Brasil dois mil,

Quem se mexer saiu (todos viram estátua).

\section{Dança da Carrocinha}

A dança da carrocinha é uma dança deliciosa,

Que coloca o joelho em terra,

Para a moça ficar formosa

Ó (fulana), levante os braços,

Ó (sicrana) sacode a saia,

Quem tiver dó de mim,

Me dá um beijo e um abraço.

\section{Futebol}

A brincadeira pode ser realizada com bolas de meia, plástico, borracha, couro ou de papel. Tudo vale a pena, para brincar em grupo, onde os participantes se dividem em 2 grupos. O campo terá em cada ponta uma barra, cada grupo defende o seu time e ganha quem faz mais gol. Antigamente, quem participava desta brincadeira eram os meninos, hoje as meninas também fazem parte do time.

\section{Pula-Corda}

A brincadeira de pula-corda pode ser individual ou com vários participantes. Individual - a criança segura a corda, uma ponta em cada mão e movimenta por cima da cabeça ou por baixo dos pés, pulando sem parar. Quando ocorre em grupo - 2 crianças, uma em cada ponta da corda, movimentam a corda sem parar e 2, 3, 4 crianças ficam no meio pulando a corda. Quem cansar ou errar primeiro sai da brincadeira.

\section{Pião}

Brinquedo em forma de pera, fabricado em madeira, com ponta de metal, onde se inicia 
a colocação do cordão até a parte superior, para jogar depois o pião no chão, onde ele começa a rodar.

\section{Esconde-Esconde}

Um grupo de crianças reunidas escolhe uma para procurar os que irão se esconder. $\mathrm{O}$ escolhido fica de costas e de olhos fechados, durante um tempo, para que os outros se escondam. Passado este tempo, começa a procura e quem ele achar primeiro será o próximo a procurar.

\section{Bola de Gude}

Bolinhas de vidro de várias cores. A brincadeira ocorre nos quintais, onde as crianças fazem a demarcação para jogar com as bolinhas. Quando consegue tocar na bolinha do companheiro, vai ganhando a bolinha; no final quem conseguiu mais bolinhas de gude será o campeão.

\section{Pipa/Papagaio}

Brinquedo feito de talas e papel de seda, com rabo de pano, em geral de forma oval ou aproximadamente triangular, que os meninos empinam preso ao barbante ou linha.

\section{Peteca}

A peteca é um dos jogos de destreza, apreciado tanto pelas crianças como pelos adultos. É geralmente jogada em grupos, mas também pode ser jogada individualmente. $\mathrm{O}$ princípio básico do jogo é o de que a peteca deve permanecer no ar, lançada de uma pessoa para a outra com a palma da mão, até que um dos jogadores a deixe cair.

\section{Bolha de Sabão}

O velho passatempo das bolhas de sabão é muito simples e exige pouco material: um recipiente com água, onde se coloca sabão comum ou em pó, e um canudo. Agita-se bem a água e, em seguida, é só assoprar através do canudo previamente embebido nesse líquido. $\mathrm{O}$ resultado varia conforme a habilidade e a criatividade do assoprador.

Ao final do projeto, além da elaboração da cartilha tivemos como resultado a capacitação dos quatro estudantes de graduação na área gerontológica, ampliando a sua formação científica; a ampliação da formação dos 10 professores da rede estadual sobre o convívio intergeracional; o aprendizado dos 180 alunos da 1. à 4. a séries sobre o respeito e a valorização dos idosos; a vivência intergeracional de forma lúdica sobre o conhecimento da cultura e da história do nosso povo através das brincadeiras de criança, recordatório das avós.

\section{Conclusão}

O projeto de extensão com abordagem intergeracional foi realizado com crianças da 1. ${ }^{\mathrm{a}}$ à $4^{\mathrm{a}}$ séries do ensino fundamental com a participação dos avós, atrelando o conhecimento com o respeito e a valorização dos idosos. Os alunos foram capacitados e sensibilizados a respeitar e tratar com atenção o próximo desde a infância; falar expressando opiniões, fatos e idéias; ouvir com atenção nas situações de interação com idosos e/ou amigos.

Todas as atividades foram elaboradas em função da solidariedade aos idosos, melhorando a autoestima e qualidade de vida dos mesmos num convívio intergeracional, minimizando os problemas de saúde decorrentes do abandono e exclusão social, bem como estimulando a aprendizagem dos alunos, de acordo com os temas abordados.

Portanto, podemos concluir que projetos com esta dimensão são importantes de serem realizados nas escolas, para que a população possa compreender melhor o processo de envelhecimento, gerando uma sociedade mais humana, respeitando e valorizando o idoso. 


\section{REFERÊNCIAS}

CAMARANO, A. M. Demografia do envelhecimento e epidemiologia. In: VERAS, R.; LOURENÇO, R. (Orgs.). Formação humana em geriatria e gerontologia: uma perspectiva interdisciplinar. Rio de Janeiro: UnATI/UERJ, 2006. p.39-57.

COELHO FILHO, J. M.; RAMOS, L. Epidemiologia do envelhecimento no Nordeste do Brasil: resultados de inquérito domiciliar. Revista de Saúde Pública, v. 33, n. 5, p. 445-453, out. 1999.

FALEIROS, V. P. Violência contra a pessoa idosa: ocorrências, vítimas e agressores. Brasília: Editora Universa, 2007.
IBGE. Perfil dos idosos responsáveis por domicílios no Brasil, 2000. Rio de Janeiro, 2002.

LEME, L. E. G.; SILVA P. S. C. P. O idoso e a família. In: PAPLEU NETTO, M. Gerontologia: a velhice e o envelhecimento em visão globalizada. São Paulo: Atheneu, 2002. p.92-97.

PEREIRA, R. S.; CURIONI, C. C.; VERAS, R. Perfil demográfico da população idosa no Brasil e no Rio de Janeiro. Textos sobre envelhecimento, Rio de Janeiro, v. 6, n.1, p.43-59, 2003.

Texto recebido em 12 de fevereiro de 2009. Texto aprovado em 17 de abril de 2009. 